\title{
The delicate topic of mentorship
}

\author{
Diana Epstein ${ }^{1,2}$ (D) $\cdot$ Igor Kozak $^{2}$
}

Received: 14 October 2019 /Revised: 14 October 2019 / Accepted: 21 October 2019/Published online: 27 November 2019

(C) Springer-Verlag GmbH Germany, part of Springer Nature 2019

Mentoring requires a generosity of time, empathy, a willingness to share knowledge, and enthusiasm [1].

During the past 20 years, the editorial office has sent annual requests to the Editorial Board - would anyone like to be a mentor-usually we receive no replies to the email. We do understand this state of affairs since mentorship can result in additional work for the board members - who may have time constraints [2] — and are usually active on editorial boards of other journals, in addition to our journal.

This year 2019, however, with a new and updated editorial board and 2 additional new editors-in-chief, a change occurred to this state of affairs.

When in January the welcome email to the editorial board was sent, we received 3 positive responses from Igor Kozak (United Arab Emirates), Tunde Peto (Belfast), and Andrzej Grzybowski (Poland). The Graefe's Archive mentorship program was launched.

Of course, we had to wait for suitable papers to be submitted and pass through the initial peer-review process.

The papers selected for the mentorship program were papers from the former Eastern European countries (Bulgaria, Czech Republic, Hungary, Poland, Romania, Russian Federation, Slovakia, Belarus, Moldova, Ukraine) [3].

Mentorship could be given to the co-authors/senior co-authors in those only papers where the whole group of authors were based in an Eastern European Country.

The papers are initially proceed as regular papers; however, upon receipt of both reviewer comments, the geographic

Diana Epstein

graefes_archive@di-ep.com

1 Di-Ep Biomedical Editorial Services Ltd, PO Box 5617, Glasgow, Scotland G77-9EH, UK

2 Moorfields Eye Hospitals UAE, Dubai, United Arab Emirates location of the authors is checked; if the paper receives a recommendation of "revision," the mentorship team is then invited to look at the paper and advise if suitable for the mentorship program.

This year, we had 1 paper which received advice from the mentorship team but the corresponding author decided to withdraw the paper; another paper which the editorial office thought would be suitable was found not to be suitable by the mentorship team since the co-authors were senior scientists based in European countries and should have offered the mentorship to the corresponding author.

However, this issue includes a paper which received input from our mentorship team [4].

We do hope that authors from former Eastern European countries will not feel disadvantaged and that we will continue to receive good scientific submissions which our mentorship team will indeed be able to help and offer advice to enable the dissemination of good science.

\section{Compliance with ethical standards}

Conflict of interest The authors declare that they have no conflict of interest.

\section{References}

1. Burgess A, van Diggele C, Mellis C (2018) Mentorship in the health profession: a review. Clin Teach 197-202

2. Cooke KJ, Patt DA, Prabhu RS (2017) The road of mentorship. Am Soc Clin Oncol Educ Book 788-792

3. https://www.newworldencyclopedia.org/entry/Eastern_Europe. Accessed 12 Oct 2019

4. Shpak AA, Korobkova MV (2019) Causes of ganglion cell-inner plexiform layer thinning in myopic eyes Grae Arch Clin Exp Ophthal (in press)

Publisher's note Springer Nature remains neutral with regard to jurisdictional claims in published maps and institutional affiliations. 